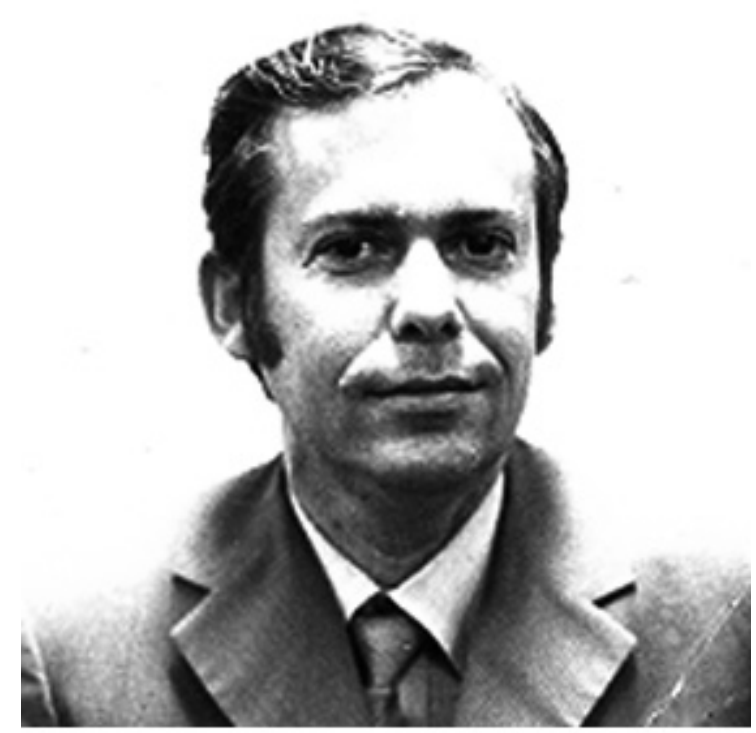

Roberto Pereda Chávez (1928-1977).

\title{
Roberto Pereda Chávez en la Salud Pública Internacional*
}

\section{Roberto Pereda Chávez in the Internacional Public Health}

\section{Francisco Rojas Ochoa}

Profesor. Escuela Nacional de Salud Pública. La Habana, Cuba.

Rendir tributo a quien lo merece no es cortesía. Es llamar a seguir el ejemplo. Por eso hoy recordamos aquí a Roberto Pereda Chávez, que en su momento fue paradigma de joven estudiante revolucionario, luego de médico entregado a la consolidación de la revolución y después aún joven, cuadro de dirección en la esfera de la salud pública. Destacó desde entonces por su serena madurez de pensamiento, fidelidad a la ideología revolucionaria y espíritu solidario. 
Pereda nació en un pequeño pueblo de la provincia de Matanzas (Carlos Rojas), el 19 de septiembre de 1928, falleció en La Habana el 15 de febrero de 1977, a los 48 años de edad. Fue un recién nacido en cuna muy modesta, su padre obrero textil, la madre modista.

En una autobiografía de las que somos requeridos frecuentemente los funcionarios, dirigentes y militantes, fechada el 18 de mayo de 1970, siete años antes de su muerte, en el párrafo titulado "Antecedentes Políticos" nos dice Pereda:

Nací y me crié en un medio familiar de militancia revolucionaria. Padre, madre y resto del núcleo familiar, miembros del Partido Unión Revolucionaria Comunista.

Desde joven tuve una formación y conducta antiimperialista. Cuando niño tuve la experiencia de conocer que personas a las que tenía simpatía y afecto (hermanos Cuervo), habían sido asesinados por la tiranía de Batista (1936).

Simpaticé y cooperé con el movimiento político liderado por Eduardo Chibás en sus últimos años.

Ingresé en el Partido Ortodoxo cuando murió Chibás y creé y presidí un Comité de Estudiantes Ortodoxos en Guanabacoa, realizando actividades de Partido en la Universidad de La Habana. Al golpe de estado de Batista el 10 de marzo de 1952, estuve en la Universidad en disposición de combatirlo hasta que se comprendió no había posibilidades, en aquel momento me enrolé en una célula del movimiento en contra de la tiranía organizado por el Partido Ortodoxo "Resistencia Pasiva."

Participé en actividades organizadas en la Universidad por el Co. Álvaro Barba.

Milité a partir del año 1954 en un grupo de acción creado dentro de la Universidad realizando actividades de sabotaje en los carnavales, participación en las manifestaciones, entrenamiento de armas, atención a heridos, perseguidos, etc.

Cooperé con el Dr. Julio Martínez Páez en las tareas del Movimiento 26 de julio antes y durante su estancia en la Sierra Maestra. Fui detenido por distribución del periódico de la FEU "Alma Mater", año 1953. Solamente estuve preso 4 días.

Fui perseguido por el Jefe del SIM Blanco Rico por estar en enrolado en un grupo de acción contra la tiranía.

Fui interrogado por el entonces Capitán Ventura por atención médica a herido perseguido. Año 1956.

Participé en años 1954 y 1955 en movimiento juvenil de oposición al régimen de Batista en el Liceo de Guanabacoa, siendo Presidente de esta Sociedad en el año 1955.

Participé en actividades del Colegio Médico Nacional en 1957-58, relacionadas con el movimiento cívico contra Batista.

Al triunfo de la Revolución me incorporé a las actividades de los médicos militares revolucionarios dentro del Partido Médico. Siendo Jefe de Despacho del Ministro de Salud Pública, Dr. José Ramón Machado Ventura, formé parte del núcleo formado en dicho Ministerio, por las Organizaciones

Revolucionarias Integradas.

Fui elegido trabajador ejemplar en el año 1963 y seleccionado como militante del Partido Comunista Núcleo de la Dirección Provincial Habana de Salud Pública. 
Fundador de las Milicias Médicas Revolucionarias.

Miembro de la Reserva militar.

Actual Secretario de Organización del Núcleo del Partido del Nivel Central del Ministerio de Salud Pública.

Participé en la ofensiva del Partido contra el Movimiento de Fracción llamado Microfracción (Pereda Chávez R. Autobiografía. Archivo familiar. La Habana 18 de mayo de 1970 . Se respeta el texto en su original).

Hasta aquí lo que podemos llamar la autobiografía política de Pereda, incompleta y redactada con gran modestia, como cuando dice: "Solamente estuve preso durante preso 4 días". Algunos revolucionarios solo estuvieron presos un día, tiempo suficiente para que los asesinaran.

Hoy nos reunimos para homenajear a un salubrista, pero un salubrista revolucionario. Recordemos que el Che, nos dijo que: ... entonces, me di cuenta de una cosa fundamental, para ser médico revolucionario, o para ser revolucionario, lo primero que hay que tener es revolución. ${ }^{1}$ Así se forjó Pereda. Primero hizo revolución, contra la tiranía, después fue médico revolucionario, cuando ya teníamos revolución.

Recordemos su historia escolar. La enseñanza primaria transcurrió en el primer año en una escuela pública, del segundo al 4to. grado en una "escuela privada de barrio", desde el 5to. grado de primaria al 1er. grado de bachillerato en las Escuelas Pías de Guanabacoa y el 5to. grado lo cursó en el Instituto No. 1 de La Habana. La carrera de medicina, entonces de 7 años, en la Universidad de La Habana, donde se graduó en marzo de 1955, a los 26 años de edad. Entre 1952 y 1955 fue alumno en la sala Gálvez (ortopedia) del Hospital Universitario "Calixto García", donde continuó de este último año hasta 1959 trabajando como médico ortopédico. También se desempeñó así del 1957 a 1960 en el Instituto Clínico de La Habana (Pereda Chávez R. Autobiografía. Archivo familiar. La Habana 18 de mayo de 1970).

Su historia laboral como salubrista se inicia en 1959, cuando su amigo y maestro, el Ministro de Salubridad y Asistencia Social, Julio Martínez Páez lo nombra su delegado, primero en la casa de Beneficencia y luego en el Instituto Nacional de Higiene. De marzo a mayo, Jefe del Servicio de Cuarentenas y simultáneamente miembro de la Comisión Nacional de Salubridad. Hasta 1960 fue Director Nacional de Servicios Médicos de la Cruz Roja Cubana. Este año fue designado Jefe de Despacho del Ministro de Salud Pública, José Machado Ventura, hasta 1962, en que pasó a ocupar el cargo de Director Provincial de Salud Pública de La Habana y posteriormente Director del hospital "Enrique Cabrera". En 1966 llegó a Director de Relaciones Internacionales del Ministerio de Salud Pública, hasta su fallecimiento (Pereda Chávez R. Autobiografía. Archivo familiar. La Habana 18 de mayo de 1970).

La diversidad de cargos, en momentos primero de depuración de los comprometidos con la tiranía en las dependencias del gobierno y luego con las iniciales manifestaciones contrarrevolucionarias, indica su clara posición sin vacilaciones al lado de la revolución y la confianza de que era acreedor en la dirección superior del Ministerio. Fue esta diversidad de cargos también una buena escuela para su vida posterior.

Las circunstancias en que un especialista en ortopedia deviniera en salubrista es la historia de numerosos médicos que se sumaron a la revolución y tuvieron que hacerse cargo de responsabilidades para las que el país no contaba con especialistas (epidemiólogos, higienistas, administradores, estadísticos sanitarios y otros). Pereda trabajó en ortopedia desde 1952 hasta 1960. Su tesis se titula 
"Traumatismo cráneo-encefálico", defendida ante un tribunal de eminentes profesores, todos titulares, de los pocos que se quedaron en sus puestos en el período revolucionario: Roberto Guerra Valdés, Enrique Hechevarría Vaillant y José Presno Albarrán. Esto es un sello de calidad, en la formación profesional de Pereda, por la conocida competencia y rigor científico del tribunal. Pero la ortopedia cedió a las necesidades de la revolución, y el ortopédico devino salubrista.

Junto a los cargos de plantilla menciona los que también ocupó, varios importantes, de carácter funcional y honorarios como Vicepresidente de la Cruz Roja Cubana (1970-1976), Presidente del Comité Ejecutivo de la Organización Panamericana de la Salud (1974-1975), Miembro del Buró Ejecutivo del Consejo de Sociedades Científicas de la Salud (1973, hasta su muerte). En 1961 fue fundador del Consejo de Dirección del Ministerio de Salud Pública, donde permaneció hasta su deceso, o sea, 16 años.

No obstante la diversidad de cargos, de diferente contenido, donde siempre se apreció su labor como muy competente cuadro de dirección, fue en el campo de las relaciones internacionales donde alcanzó mayor brillantez y resultados concretos de valor para la salud pública cubana.

Una nuestra de ello la podemos apreciar por las frecuentes reuniones de muy distinto perfil político y técnico en que representó a Cuba y defendió nuestra revolución cuando fue necesario, presentó nuestros resultados y concretó acuerdos beneficiosos para el país.

Participó como delegado o jefe de delegación en siete reuniones de Ministros de Salud Pública de Países Socialistas entre 1966 y 1976. Fue presidente del secretariado de la reunión de 1974. En la reunión de 1969 presentó el tema "La Asistencia Hospitalaria en Cuba."

Fue delegado o presidente de la delegación cubana en seis Asambleas Mundiales de la Salud. En la de 1969, celebrada en Boston, EE. UU. presentó el tema "Informe sobre la salud pública en Cuba."

En la Asamblea del año 1973 fue electo vicepresidente de la Comisión A, una de las dos en que se divide el Pleno. Este cargo y el de Presidente del Comité Ejecutivo de la organización Panamericana de la Salud, solo un cubano lo ha ocupado en lo últimos 50 años, el Dr. Pereda Chávez.

Participó como delegado de Cuba en las Conferencias Sanitarias Panamericanas de 1962, 1966, 1970 y 1974. Así como en siete Consejos Directivos de la Organización Panamericana de la Salud entre 1963 y 1976, actuando como Presidente en 1975. Fue miembro del Comité Ejecutivo de esta organización entre 1973 y 1976 y presidió la reunión del Comité de octubre de 1974, cuando fue elegido su presidente por unanimidad.

De todas estas reuniones están recogidas sus intervenciones en las actas de estas dos organizaciones internacionales. Un muestra de ellas es su exposición sobre la política y planes de incremento acelerado de la formación de personal calificado para cubrir la demanda del momento y perspectivas del sistema de salud cubano, intervención que hizo en la xviII Reunión del Consejo Directivo de la Organización Panamericana de la Salud, según consta en el Acta Resumida de la Segunda Sesión Plenaria de la reunión celebrada en Buenos Aires el 14-15 de octubre de 1968.

En su serie de artículos titulada "Precursores y forjadores de la salud pública cubana, Dr. Roberto Pereda Chávez (1928-1977)", el profesor Gregorio Delgado 
García nos dice respecto a la gestión de Pereda como Director de Relaciones Internacionales del Ministerio de Salud Pública lo siguiente:

Para tan importante cargo estaba especialmente preparado política, científica y culturalmente el doctor Pereda Chávez, quien además había tenido algunas experiencias en el campo internacional que a la vez lo adiestraron, le dieron discreción, el tacto y la sutileza tan necesarios en estos desempeños. ${ }^{2}$

Certero juicio este del Profesor Delgado sobre el Dr. Pereda Chávez.

Puedo añadir su transparencia negociando un convenio, su comunicación con visitantes a los que preparaba un programa, la pudicia en toda su conducta.

Otras numerosas tareas se reflejan en acciones en relación con sus responsabilidades internacionales. Así visitó varios países de Europa del Este con el propósito de estudiar su organización de salud. Los países fueron Unión Soviética, Bulgaria, Hungría, República Democrática Alemana y Checoslovaquia. Asistió en 1962 a la Reunión Internacional de Sociedades de la Cruz Roja. Visitó a Argelia para el análisis y proyección de la cooperación en salud iniciada pocos años antes.

En ocasión de un homenaje póstumo en fecha cercana a su deceso el Profesor Arnaldo Tejeiro Fernández dijo:

Durante este intenso trabajo internacional, en particular en las organizaciones de América, supo Pereda aprovechar la oportunidad de divulgar las transformaciones y éxitos de la salud pública cubana y lo que es más, la realidad de nuestro proceso revolucionario, enarbolando con vehemencia la defensa de sus principios. Esto que es actualmente cada vez más accesible frente al conocimiento creciente de las realidades de nuestra revolución en el terreno internacional, resulta de indiscutible importancia en los primeros años, cuando al imperialismo norteamericano no le alcanzó la fuerza para bloquear nuestra presencia en los organismos de salud de América, los que constituyeron durante algún tiempo la única tribuna de expresión, dentro de los organismos gubernamentales interamericanos (Tejeiro Fernández A. En memoria del Dr. Roberto Pereda Chávez. Trabajo leído en la sesión científica de la Sociedad de Historia de la Medicina del 19 de abril de 1977. Museo de las Ciencias Médicas "Carlos J. Finlay". Consultado en archivo familiar).

Cuando el niño Roberto cumplió dos años, se trasladó con su familia a residir en la villa de Guanabacoa, hasta después del triunfo de la revolución, momento de su traslado al barrio de Altahabana, muy poblado por médicos. Su larga residencia en Guanabacoa lo identificó plenamente con esta población de vieja y notable historia. Nos recordaba al héroe de la villa Pepe Antonio, hablaba con respeto del gran compositor Ernesto Lecuona, fue amigo personal de Ignacio Villa (Bola de Nieve).

Su vínculo estrecho con esta comunidad le permitió ser aceptado como miembro del Liceo Artístico y Literario de Guanabacoa, institución de la que fue electo presidente en 1955. Esta posición lo identifica como persona de inquietudes humanísticas y artísticas.

Esto me hace recordar su apoyo continuo al Profesor José M. Vidal Yebra cuando organizaba exposiciones de pintura en el vestíbulo del 2do. piso del edificio del Ministerio de Salud Pública. 
Pereda gozó de la amistad de numerosas personalidades políticas y artísticas, como Raúl Roa, René Portocarrero, Eusebio Leal, entre otros.

Buscando ampliar su horizonte científico, fue miembro de la Sociedad Cubana de Historia de la Medicina y de la Sociedad Cubana de Salud Pública.

Como revolucionario no descuidaba su contacto con organizaciones en sus bases: cederista, miliciano, atendiendo al sindicato y a la juventud. Cumpliendo las correspondientes guardias, asistiendo a concentraciones y a toda forma de convocatoria a la lucha política.

Al morir Pereda se separaba de la familia que había formado: su esposa Elsa, sus hijas Celia María y Elsa María y su mamá Celia. Al rendir tributo a Roberto Pereda, para sus familiares nuestro respeto y aprecio por el amor y felicidad que le dieron a nuestro entrañable compañero, apoyo indispensable para su quehacer cotidiano.

Con posterioridad a su fallecimiento la Organización Panamericana de la Salud le otorgó el Premio Anual por Administración de Salud del año 1977.

\section{REFERENCIAS BIBLIOGRÁFICAS}

1. Guevara E. Discurso inauguración de un ciclo de charlas para trabajadores del Ministerio de Salud Pública (19.08.60). En: Guevara habla a la juventud. La Habana: Casa Editora Abril; 2001. p. 43-56.

2. Delgado García G. Dr. Roberto Pereda Chávez (1928-1977). Serie: precursores y forjadores de la salud pública cubana. Rev Cubana Salud Pública. 1996; No. 2.

Recibido: 5 de enero de 2011.

Aprobado: 16 de febrero de 2011.

Francisco Rojas Ochoa. Escuela Nacional de Salud Pública. Calle 100 No. 10132 e/ Perla y E. Altahabana, Boyeros. La Habana, Cuba.

Correo electrónico: concuba@infomed.sld.cu

*Intervención en el simposio Roberto Pereda Chávez in memoriam. Escuela Nacional de salud Pública. La Habana, 16 de febrero de 2011. 